\title{
Abdominal compartment syndrome: Incidence and prognostic factors influencing survival in Singapore
}

\author{
Chok Aik-Yong, Koh Ye-Xin, Ng Shin Yi ${ }^{1}$, Wong Ting Hway
}

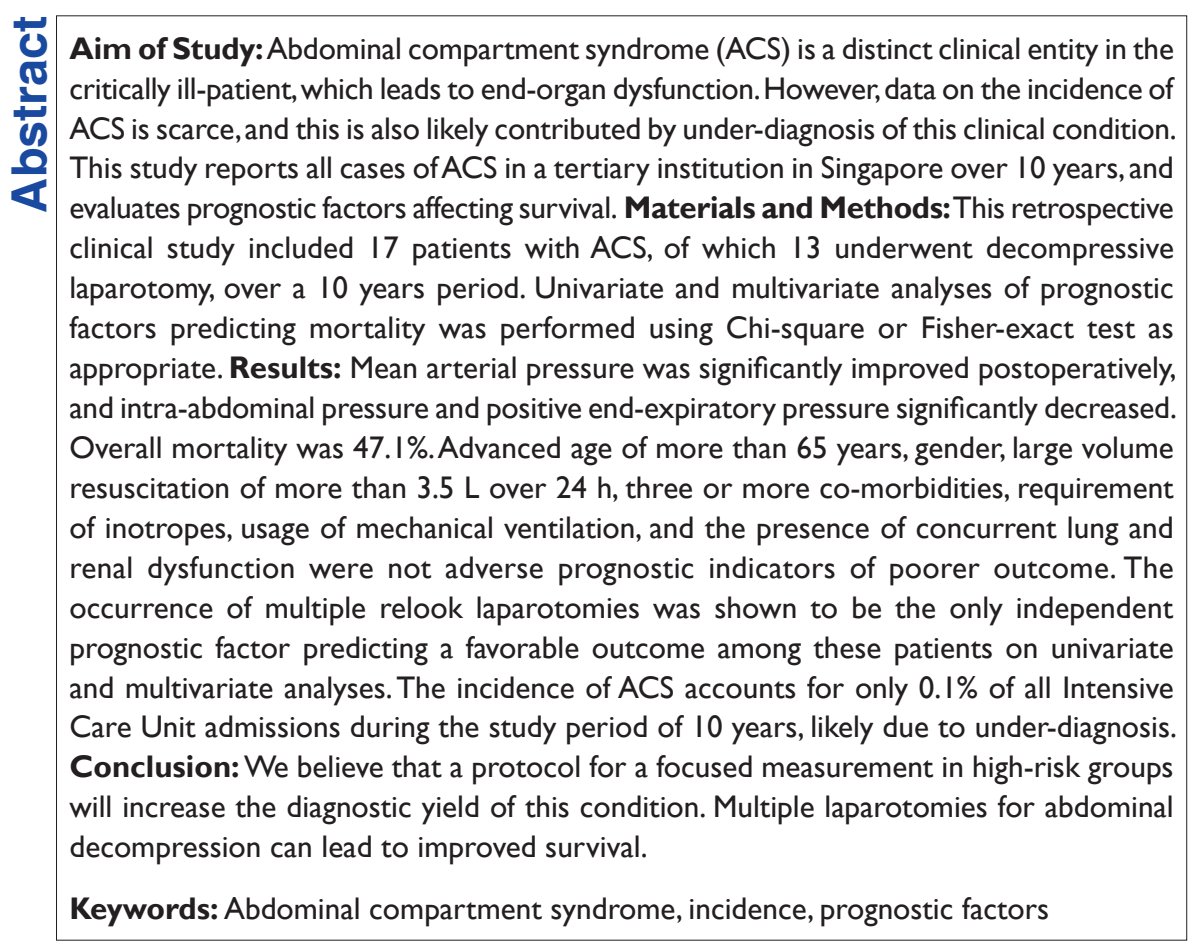

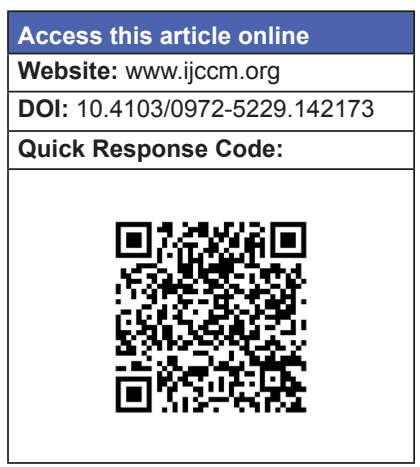

\section{Introduction}

Abdominal compartment syndrome (ACS) is defined as a state of intra-abdominal hypertension (IAH) resulting in the end-organ dysfunction. The term was first coined in 1984 by Kron et al., who reported significant mortality associated with this syndrome and suggested that surgical decompression be carried out in addition to investigation and treatment of the underlying cause. ${ }^{[1]}$ Subsequently, various authors have reported the benefits of abdominal decompression as the primary treatment

From:

Departments of General Surgery and ${ }^{1}$ Anaesthesia and Critical Care, Singapore General Hospital, Singapore

Correspondence:

Dr. Wong Ting Hway, Department of General Surgery, Singapore General Hospital, 20 College Road, Level 5 Academia, Singapore 169856.

E-mail: wong.ting.hway@sgh.com.sg modality. ${ }^{[2,3]}$ Over the years, IAH and ACS have been increasingly recognized as a distinct clinical entity, prompting the formation of the World Congress on ACS for the standardization of definitions and guidelines on the diagnosis and management of this condition.

The aim of the current study is to review the incidence, causative and contributing factors, clinical course and outcome of all detected cases of ACS in our institution.

\section{Materials and Methods}

This was a retrospective review of all the patients diagnosed with ACS from the January 1, 2002 to January 1,2013 . The cases were identified from the morbidity and mortality reports in our general surgery department database. Data regarding the diagnosis of ACS, details of 
the intervention including nonoperative and operative management, clinical course and outcomes, were obtained from a retrospective review of computerized records and case notes. Patients operated on for the diagnosis of compartment syndrome, patients whose mortality report included a diagnosis of compartment syndrome, and all cases of temporary abdominal closure performed for reasons other than ACS were reviewed. The indication for temporary abdominal closure for each case was evaluated individually, where cases that underwent temporary abdominal closure for the reasons of excessive tension or expected tension in event of closure were deemed by the attending surgeon were identified.

The following parameters were taken from retrospective case note review: Age, gender, clinical/surgical status, diagnoses, Acute Physiology and Chronic Health Evaluation (APACHE) II score, previous abdominal surgery, the abdominal infection (pancreatitis, abscess, others), massive fluid resuscitation defined as $>3.5 \mathrm{~L}$ over $24 \mathrm{~h}$, hypotension, inotropic support, acidosis, multiple transfusions, mechanical ventilation, pneumonia, bacteremia, or acute respiratory distress syndrome and clinical outcomes were recorded. ${ }^{[4]}$

Intra-abdominal pressure was measured in millimeters of mercury through a Foley bladder catheter using the pressure transducer. The method we employ is similar to that outlined in the consensus statement. ${ }^{[5]}$

\section{Statistical analysis}

All statistical analyses were conducted by SPSS for Windows version 17.0 (SPSS, Chicago, IL). Univariate analysis of prognostic factors predicting mortality was performed using Chi-square or Fisher-exact test as appropriate. Factors identified as statistically significant by univariate analysis were evaluated by multivariate analysis using the Cox regression model. All tests were two-sided, and $P=0.05$ was considered as statistically significant.

\section{Results}

Seventeen patients were diagnosed with ACS in the surgical Intensive Care Unit (SICU) during the 10 years study period. There were 43 patients with temporary abdominal closure performed during the initial laparotomy, due to reasons including difficulty closing primarily, high likelihood of development of IAH or ACS upon closure and need for further surgery after resuscitation in the SICU. Among these 43 patients, five underwent two or more relook laparotomies and subsequent temporary abdominal closure. In the same group of patients, six were deemed to be at high risk of IAH upon primary abdominal closure; hence temporary abdominal closure was performed at the outset. These six patients were included in the study.

As for the 17 patients who met the criteria of ACS, they were between the age of 17 and 87 (median age 68), and eight of them were male. Primary ACS was recognized in 14 of these patients while the remaining three patients were deemed to have secondary ACS. Nine patients had three or more co-morbidities including diabetes mellitus, hypertension, and ischemic heart disease, prior to illness. Median APACHE II score was 21 (10-28). Eleven patients received more than $3.5 \mathrm{~L}$ of fluid resuscitation in the form of crystalloids, colloids, or blood products, in the preceding $24 \mathrm{~h}$.

The causes of ACS are summarized in Table 1.

The most frequently compromised organ resulting from ACS was the lung, with 15 patients requiring mechanical ventilation with median positive end-expiratory pressures (PEEP) of 15. Concurrent renal dysfunction requiring dialysis was observed in 11 of these patients. Thirteen patients underwent decompressive laparotomy, of which seven required subsequent relook laparotomies. The mean physiological parameters such as intra-abdominal pressure (IAP) and mean arterial pressure (MAP) were compared preoperatively as well as at $12 \mathrm{~h}$ postoperatively.

The postoperative effects of decompressive laparotomy performed on 13 patients are seen in Table 2. Mean preoperative IAP of these patients was $27.17 \mathrm{mmHg}$ (19.00-38.00), while mean postoperative IAP was $5.50 \mathrm{mmHg}(3.00-9.00)$. One patient with IAP of $19 \mathrm{mmHg}$ and severe impairment of end-organ perfusion underwent decompressive laparotomy, while all the other patients had IAP of $20 \mathrm{mmHg}$ or more (four

Table I: Causes of abdominal compartment syndrome among 17 patients

\begin{tabular}{lc}
\hline Cause & Number of patients \\
\hline Primary ACS & 5 \\
Abdominal sepsis & 2 \\
Abdominal surgery & 4 \\
Severe acute pancreatitis & 4 \\
Intra-abdominal bleeding & \\
Secondary ACS & $\mathrm{I}$ \\
Severe bilateral pneumonia and ARDS & $\mathrm{I}$ \\
CCF and castleman's disease lymphoma & \\
\hline
\end{tabular}

ACS: Abdominal compartment syndrome; ARDS: Acute respiratory distress syndrome; CCF: Congestive cardiac failure 
patients had IAP exceeding $30 \mathrm{mmHg}$ ). There is a statistically significant decrease in IAP and PEEP after decompressive laparotomy, as well as increase in MAP.

Overall mortality was $47.1 \%$; nine patients survived and were discharged from the hospital stable. The median duration of hospital stay was 28 days (4-348), with 10 days (1-68) spent in the SICU. Univariate analysis of factors predicting mortality demonstrated that advanced age of more than 65 years, gender, large volume resuscitation of more than $3.5 \mathrm{~L}$ over $24 \mathrm{~h}$, three or more co-morbidities, requirement of inotropes, usage of mechanical ventilation, and the presence of concurrent lung and renal dysfunction were not adverse prognostic indicators of poorer outcome. Using the two sample $t$-test, the comparison of the APACHE II scores showed no statistically significant difference between the mortality group and the group of patients who eventually survived (mean score: 20.25 vs. 20.33, $P=0.354)$.

Of the 13 patients who were subjected to decompressive laparotomy, six subsequently demised. The proportion of patients who survived among the remaining four managed conservatively was similar, with two patients who passed away. Among the six patients who underwent surgery, but died, five succumbed after the first surgery. As for the seven patients who made it past the first decompressive laparotomy, all underwent temporary closure of the abdomen and thence subsequent relook laparotomies. Six patients survived; one of them underwent as many as nine relook laparotomies, as detailed in Table 3.

Table 2: Postoperative effects of decompressive laparotomy on 13 patients

\begin{tabular}{lcc}
\hline Variable & $\mathbf{Z}$ & $\boldsymbol{P}$ \\
\hline PEEP after-PEEP before & $-2.375^{\mathrm{a}}$ & $0.018^{\mathrm{c}}$ \\
IAP after-IAP before & $-3.185^{\mathrm{a}}$ & $0.00 \mathrm{I}^{\mathrm{c}}$ \\
MAP after-MAP before & $-3.180^{\mathrm{b}}$ & $0.00 \mathrm{I}^{\mathrm{c}}$ \\
\hline aBased on positive ranks; ${ }^{\mathrm{b}}$ Based on negative ranks; ${ }^{\mathrm{c}}$ Wilcoxon signed ranks test. \\
PEEP: Positive end-expiratory pressures; IAP: Intra-abdominal pressure; MAP: Mean \\
arterial pressure
\end{tabular}

The occurrence of subsequent relook laparotomies was found to be the only statistically significant factor predicting survival in the univariate analysis. Notably, patients with higher scores on the APACHE II system were not shown to fare worse on both univariate and multivariate analyses. As seen in Table 4, independent prognostic factors such as advanced age, number of co-morbidities, requirement of mechanical ventilation or inotropic support, and concurrent dual-organ (lung and renal) dysfunction did not portend a worse prognosis on univariate analysis.

Two other factors appeared to adversely influence survival: The use of $>3.5 \mathrm{~L}$ fluid resuscitation and the presence of concurrent lung and renal dysfunction, although the $P$ value did not reach statistical significance. Multivariate analysis was performed, which suggested once again that patients who underwent subsequent relook laparotomies for ACS tended to have a more favorable clinical outcome. Refer to Tables 4 and 5 .

\section{Discussion}

Numerous risk factors for the development of IAH and/or ACS have been suggested. Three large-scale prospective trials have identified independent risk factors for the development of IAH/ ACS. Malbrain et al . identified that abdominal surgery, high-volume fluid resuscitation $(>3500 \mathrm{ml} / 24 \mathrm{~h})$, ileus, and pulmonary, renal, or liver dysfunction predict IAH in a mixed medical-surgical population. ${ }^{[4]}$ Ivatury et al. identified that the severity of abdominal trauma, lactate level, and use of temporary abdominal closure are predictors of survival among penetrating trauma patients with ACS. ${ }^{[6,7]}$ Balogh et al. identified hypothermia, acidosis, anemia, oliguria, high crystalloid resuscitation volume, and high gastric regional minus end-tidal carbon dioxide tension as predictors of ACS in blunt thoracoabdominal trauma patients. ${ }^{[8]}$ Despite the knowledge of these well-studied factors, the relative contribution of each of these factors to the development of IAH and ACS are still not known. In fact, many of these factors

\begin{tabular}{|c|c|c|c|c|}
\hline Patients & Underlying pathology & $\begin{array}{c}\text { Total number } \\
\text { re-look laparotomies }\end{array}$ & $\begin{array}{l}\text { Time to definitive } \\
\text { closure (days) }\end{array}$ & $\begin{array}{l}\text { Type of } \\
\text { closure }\end{array}$ \\
\hline $\mathrm{I}$ & Ileus and small bowel edema & 4 & 7 & Other I \\
\hline 2 & Post AAA repair bleeding & 3 & 5 & Simple \\
\hline 3 & Perforated appendicitis/generalized purulent peritonitis & 5 & 9 & Simple \\
\hline 4 & Post AAA repair bleeding & 7 & 34 & Other 2 \\
\hline 5 & Severe hemorrhagic acute pancreatitis Ransons 8 & 4 & NA & NA \\
\hline 6 & Liver abscess $10 \mathrm{~cm}$ & 9 & 37 & Simple \\
\hline 7 & Severe bilateral pneumonia and ARDS & 2 & 5 & Simple \\
\hline
\end{tabular}

Other I: Component separation (no mesh); Other 2: Progressive VAC change till granulation tissue seen, then split skin graft; NA: Not available, as patient 5 demised before definitive closure of abdomen. VAC: Vacuum-assisted closure; AAA: Abdominal aortic aneurysm; ARDS: Acute respiratory distress syndrome 


\begin{tabular}{|c|c|c|c|}
\hline Variable & $\begin{array}{c}\text { Mortality/ } \\
\text { total patients }\end{array}$ & OR & $P$ \\
\hline \multicolumn{4}{|l|}{ Age } \\
\hline Age $<65$ & $4 / 8$ & I & \\
\hline Age $\geq 65$ & $4 / 9$ & $0.80(0.19-5.40)$ & $1.000^{\mathrm{b}}(\mathrm{NS})$ \\
\hline \multicolumn{4}{|l|}{ Gender } \\
\hline Female & $3 / 9$ & I & \\
\hline Male & $5 / 8$ & $3.33(0.46-24.44)$ & $0.347^{b}(\mathrm{NS})$ \\
\hline \multicolumn{4}{|l|}{$\begin{array}{l}\text { Volume of fluid resuscitation } \\
\text { in preceding } 24 \mathrm{~h}\end{array}$} \\
\hline$<3.5 \mathrm{~L}$ fluid resuscitation & $1 / 6$ & I & \\
\hline$\geq 3.5 \mathrm{~L}$ fluid resuscitation & $7 / 11$ & $8.75(0.74-103.82)$ & $0.13 \mathrm{I}^{\mathrm{b}}(\mathrm{NS})$ \\
\hline \multicolumn{4}{|l|}{ Co-morbidities } \\
\hline$<3$ comorbidities & $5 / 8$ & I & \\
\hline$\geq 3$ comorbidities & $3 / 9$ & $0.30(0.04-2.20)$ & $0.347^{b}(\mathrm{NS})$ \\
\hline \multicolumn{4}{|l|}{$\begin{array}{l}\text { Requirement of mechanical } \\
\text { ventilation }\end{array}$} \\
\hline No & $1 / 3$ & I & \\
\hline Yes & $7 / 14$ & $2.00(0.15-27.45)$ & $1.000^{\mathrm{b}}(\mathrm{NS})$ \\
\hline \multicolumn{4}{|l|}{$\begin{array}{l}\text { Presence of hypotension } \\
\text { requiring inotropes }\end{array}$} \\
\hline No & $1 / 2$ & I & \\
\hline Yes & $7 / 15$ & $0.88(0.05-16.74)$ & $1.000^{\mathrm{b}}(\mathrm{NS})$ \\
\hline \multicolumn{4}{|l|}{ APACHE II score } \\
\hline$\leq 15$ & $2 / 4$ & I & \\
\hline$>15$ & $6 / 13$ & $1.08(0.35-3.40)$ & $1.000^{\mathrm{b}}(\mathrm{NS})$ \\
\hline \multicolumn{4}{|l|}{$\begin{array}{l}\text { Concurrent lung and renal } \\
\text { dysfunction }\end{array}$} \\
\hline No & $2 / 6$ & I & \\
\hline Yes & $6 / 11$ & $2.40(0.30-19.04)$ & $0.620^{\mathrm{b}}(\mathrm{NS})$ \\
\hline \multicolumn{4}{|l|}{$\begin{array}{l}\text { Decompressive } \\
\text { laparotomy }\end{array}$} \\
\hline No & $2 / 4$ & I & \\
\hline Yes & $6 / 13$ & $0.86(0.09-8.08)$ & $1.000^{\mathrm{b}}(\mathrm{NS})$ \\
\hline \multicolumn{4}{|l|}{$\begin{array}{l}\text { Subsequent relook } \\
\text { laparotomy }\end{array}$} \\
\hline No & $5 / 6$ & I & \\
\hline Yes & $1 / 7$ & $0.03(0.01-0.68)$ & $0.029^{b}$ \\
\hline
\end{tabular}

\begin{tabular}{|c|c|c|c|}
\hline Factor & $\begin{array}{l}\text { Adjusted } \\
\text { OR }\end{array}$ & $95 \% \mathrm{Cl}$ & $P$ value \\
\hline \multicolumn{4}{|c|}{$\begin{array}{l}\text { Volume of fluid resuscitation in } \\
\text { preceding } 24 \mathrm{~h}\end{array}$} \\
\hline$<3.5 \mathrm{~L}$ fluid resuscitation & I & & \\
\hline$\geq 3.5 \mathrm{~L}$ fluid resuscitation & 2.888 & $0.003-1.500$ & 0.089 (NS) \\
\hline \multicolumn{4}{|l|}{ APACHE II score } \\
\hline$\leq 15$ & 1 & & \\
\hline$>15$ & 0.013 & $0.027-24.682$ & 0.909 (NS) \\
\hline \multicolumn{4}{|l|}{ Subsequent relook laparotomy } \\
\hline No & I & & \\
\hline Yes & 3.807 & $0.986-504.38 \mid$ & 0.051 \\
\hline
\end{tabular}

are ubiquitous in a significant proportion of surgical patients and might not be helpful in predicting those who might eventually develop ACS. Thus, unless measurement of IAP becomes a routine process in ICU care for the identified high-risk patients, many of the patients with IAH might remain undiagnosed until the process becomes a fulminant ACS.

It has been proven in multiple studies that IAH results in decreased intra-abdominal organ perfusion and impairment of cardiovascular function as a result of reduced venous return account for the harmful effects. ${ }^{[9-11]}$ In its more severe state, ACS has been associated with a dismal prognosis with as low as $20 \%$ survival. ${ }^{[10,11]}$ This was similarly shown in our study where we had $47.1 \%$ mortality for ACS patients. Based on the multivariate analysis of our patients, the only factor which favorably influenced mortality was subsequent laparotomies, which was shown to be significant even after severity of illness was controlled for. Our multivariate analysis suggests that we should not be in a hurry to close the abdomen despite the apparent morbidity from repeat laparotomies. However, we should be circumspect with the interpretation of this result, taking into consideration the likely influence of survival bias in this cohort of patients with a high mortality rate reported. Indeed, although we believe that multiple laparotomies are a fundamental factor in ensuring a good outcome (i.e. survival), it is also conceivable that it is only among the patients who survive, that we are able to perform multiple laparotomies, and hence ultimately resulting in eventual survival of these patients.

In a prospective 9 months study by Vidal et al., 12\% of the 83 eligible mixed ICU patients actually fulfilled the diagnostic criteria for ACS. This was a significant proportion of all ICU patients. ${ }^{[1]]}$ In comparison, in the study period of 10 years in our institution, only 17 patients were diagnosed with ACS out of a total of 13525 ICU admissions from the medical and surgical ICUs. There were 5925 admissions from the medical ICUs and 7600 admissions to the surgical ICU. The incidence of ACS in our study accounts for only $0.1 \%$ of all ICU admissions during that period. Although ACS has been formalized by consensus definitions and guidelines from 2006, the incidence of ACS detected per year as shown in our study, has not increased when compared to the incidence shown in the study which was reported by Vidal et al. ${ }^{[5,11,12]}$

In the same period, there were 43 cases of temporary abdominal closures for which intra-abdominal pressures were not measured. In these cases, there was clinical suspicion by the attending surgeon to anticipate a closure under tension that might in turn lead to IAH. If these 43 cases of temporary abdominal closure were assumed to develop ACS if temporary closure were not performed, the incidence of ACS in the past 10 years would be $(n=60 / 13,525)$ at $0.44 \%$ of all ICU admissions. 
This is grossly below the expected incidence of ACS when compared to all the other institutions. We believe that as ACS was not a well-documented clinical entity until it gained significant prominence and recognition in the early millennium, there was a possibility that ACS was under-diagnosed in our study period.

Indeed since IAH and ACS have been increasingly recognized worldwide, there have been many centers showing a significant proportion of their at risk patients developing IAH and ACS. In a medical ICU setting with 468 patients admitted over an 8 months period, 40 patients were identified as at risk patients as they received $>5 \mathrm{~L}$ of fluid in the preceding $24 \mathrm{~h}$. Significantly, $34 / 40(85 \%)$ of those patients developed IAH and eventually 13/40 (33\%) developed ACS. ${ }^{[13]}$ In another surgical-medical ICU study of 81 consecutive patients in septic shock, 67/81 (82.7\%) of those patients developed IAH in $72 \mathrm{~h}$ period. Twenty-six out of 67 patients with IAH eventually progressed to ACS. ${ }^{[14]}$ In another 9 months study at the ICU of a level 1 trauma center, 15/706 (2\%) consecutive trauma patients were diagnosed with IAH and 6/15 eventually progressed to ACS. ${ }^{[15]}$

This review thus shows that if IAP were measured routinely in all ICU patients, the diagnostic yield might not be significant enough to justify the effort. In contrast, focused monitoring for the at-risk groups shows that we can achieve a significant detection rate of IAH and detect eventual ACS in those patients. In conclusion, IAH and ACS are under-diagnosed entities in our patient population and protocol for a focused measurement in high-risk groups will increase the diagnostic yield of this condition. It is hoped that early identification and institution of interventions can improve the outcome in these patients.

\section{References}

1. Kron IL, Harman PK, Nolan SP. The measurement of intra-abdominal pressure as a criterion for abdominal re-exploration. Ann Surg 1984;199:28-30

2. Eddy V, Nunn C, Morris JA Jr. Abdominal compartment syndrome.
The Nashville experience. Surg Clin North Am 1997;77:801-12.

3. Meldrum DR, Moore FA, Moore EE, Franciose RJ, Sauaia A, Burch JM. Prospective characterization and selective management of the abdominal compartment syndrome. Am J Surg 1997;174:667-72.

4. Malbrain ML, Chiumello D, Pelosi P, Bihari D, Innes R, Ranieri VM, et al. Incidence and prognosis of intra-abdominal hypertension in a mixed population of critically ill patients: A multiple-center epidemiological study. Crit Care Med 2005;33:315-22.

5. Malbrain ML, Cheatham ML, Kirkpatrick A, Sugrue M, Parr M, De Waele J, et al. Results from the International Conference of Experts on Intra-abdominal Hypertension and Abdominal Compartment Syndrome. I. Definitions. Intensive Care Med 2006;32:1722-32.

6. Ivatury RR, Porter JM, Simon RJ, Islam S, John R, Stahl WM. Intra-abdominal hypertension after life-threatening penetrating abdominal trauma: Prophylaxis, incidence, and clinical relevance to gastric mucosal $\mathrm{pH}$ and abdominal compartment syndrome. J Trauma 1998;44:1016-21.

7. Ivatury RR, Cheatham ML, Malbrain ML, Sugrue M. Abdominal Compartment Syndrome. Georgetown: Landes Biosciences; 2006.

8. Balogh Z, McKinley BA, Holcomb JB, Miller CC, Cocanour CS, Kozar RA, et al. Both primary and secondary abdominal compartment syndrome can be predicted early and are harbingers of multiple organ failure. J Trauma 2003;54:848-59.

9. Duperret S, Lhuillier F, Piriou V, Vivier E, Metton O, Branche P, et al. Increased intra-abdominal pressure affects respiratory variations in arterial pressure in normovolaemic and hypovolaemic mechanically ventilated healthy pigs. Intensive Care Med 2007;33:163-71.

10. Balogh Z, McKinley BA, Cox Jr CS, Allen SJ, Cocanour CS, Kozar RA, et al. Abdominal compartment syndrome: The cause or effect of postinjury multiple organ failure. Shock 2003;20:483-92.

11. Vidal MG, Ruiz Weisser J, Gonzalez F, Toro MA, Loudet C, Balasini C, et al. Incidence and clinical effects of intra-abdominal hypertension in critically ill patients. Crit Care Med 2008;36:1823-31.

12. Cheatham ML, Malbrain ML, Kirkpatrick A, Sugrue M, Parr M, De Waele J, et al. Results from the international conference of experts on intra-abdominal hypertension and abdominal compartment syndrome. II. Recommendations. Intensive Care Med 2007;33:951-62.

13. Daugherty EL, Hongyan Liang, Taichman D, Hansen-Flaschen J, Fuchs BD. Abdominal compartment syndrome is common in medical Intensive Care Unit patients receiving large-volume resuscitation. J Intensive Care Med 2007;22:294-9.

14. Regueira T, Bruhn A, Hasbun P, Aguirre M, Romero C, Llanos O, et al. Intra-abdominal hypertension: Incidence and association with organ dysfunction during early septic shock. J Crit Care 2008;23:461-7.

15. Hong JJ, Cohn SM, Perez JM, Dolich MO, Brown M, McKenney MG. Prospective study of the incidence and outcome of intra-abdominal hypertension and the abdominal compartment syndrome. Br J Surg 2002;89:591-6.

How to cite this article: Aik-Yong C, Ye-Xin K, Yi NS, Hway WT. Abdominal compartment syndrome: Incidence and prognostic factors influencing survival in Singapore. Indian J Crit Care Med 2014;18:648-52.

Source of Support: Nil, Conflict of Interest: None declared. 